\title{
Phenolic Profile and Bioactive Properties of Carissa macrocarpa (Eck1.) A.DC.: An In Vitro Comparative Study between Leaves, Stems, and Flowers
}

\author{
Fedia Souilem ${ }^{1,2, \dagger}$, Maria Inês Dias ${ }^{1,+}{ }^{,}$Lillian Barros ${ }^{1}\left(\mathbb{D}\right.$, Ricardo C. Calhelha $^{1}(\mathbb{D}$, \\ Maria José Alves ${ }^{1}$, Fethia Harzallah-Skhiri ${ }^{2}$ and Isabel C.F.R. Ferreira ${ }^{1, *(D)}$ \\ 1 Centro de Investigação de Montanha (CIMO), Instituto Politécnico de Bragança, Campus de Santa Apolónia, \\ 5300-253 Bragança, Portugal; souilemfedia@gmail.com (F.S.); maria.ines@ipb.pt (M.I.D.); lillian@ipb.pt (L.B.); \\ calhelha@ipb.pt (R.C.C.); maria.alves@ipb.pt (M.J.A.) \\ 2 Laboratoire de Recherche "Bioressources": Biologie Intégrative \& Valorisation (BIOLIVAL) LR14ES06, \\ Institut Supérieur de Biotechnologie de Monastir, Avenue Tahar Hadded, BP 74,5000, Université de Monastir, \\ Monastir 5000, Tunisia; fethiaprosopis@yahoo.fr \\ * Correspondence: iferreira@ipb.pt; Tel.: +351-273-303219; Fax: +351-273-325405 \\ + These authors contributed equally to this work.
}

Received: 16 April 2019; Accepted: 28 April 2019; Published: 30 April 2019

check for updates

\begin{abstract}
The present work aimed to characterize leaves, stems, and flowers of Carissa macrocarpa (Eckl.) A.DC., by performing an analysis of the phenolic compounds by HPLC-DAD/ESI-MS, correlating them with bioactive properties, such as antioxidant, anti-inflammatory, cytotoxic, and antimicrobial activities. Thirty polyphenols were identified in the hydroethanolic extract, including phenolic acids, flavan-3-ols, and flavonol glycosides derivatives (which presented the highest number of identified compounds). However, flavan-3-ols showed the highest concentration in stems (mainly owing to the presence of dimers, trimmers, and tetramers of type B (epi)catechin). Leaves were distinguished by their high antioxidant and anti-inflammatory activities, as well as their bactericidal effect against $E$. coli, while stems presented a higher cytotoxic activity and bactericidal effect against Gram-positive bacteria. Moreover, a high correlation between the studied bioactivities and the presence of phenolic compounds was also verified. The obtained results bring added value to the studied plant species.
\end{abstract}

Keywords: Carissa macrocarpa; plant aerial parts; phenolic profile; bioactivities; Pearson's correlation

\section{Introduction}

The genus Carissa belongs to the family of Apocynaceae, which normally has a high content of phenolic compounds, such as flavonoids, as well as lignans and sesquiterpenes. Accordingly, this plant genus presents several therapeutic applications such as antioxidant, analgesic, anti-inflammatory, hypolipidemic, wound healing, antimicrobial, antidiabetic, antiepileptic, anti-cancer, diuretic, hepatoprotective, and improvement of nephrotoxicity [1].

Carissa macrocarpa (Eckl.) A.DC. (syn: C. grandiflora (E.Mey.) A.DC.) is a native plant from South Africa, KwaZulu-Natal, commonly known as Natal plum [2,3]. It is an ornamental shrub, characterized by large, green, lush, and persistent leaves; star-shaped and white flowers; and edible oval fruits $[3,4]$. The ripe fruits are delicious and can be used for the preparation of jams, sauces, desserts, yogurt, jellies, and ice cream, while this plant is also used in traditional medicine for the treatment of diarrhea in livestock, cough, and venereal diseases $[5,6]$. C. macrocarpa leaves, stems, and roots present antioxidant and antimicrobial activities [3,4], and the leaves present cytotoxic activity [7], 
owing to the presence of various secondary metabolites, such as flavonoids, saponins, triterpenoids, anthraquinones, and tannins

The presence of different phenolic compounds, such as flavonoids, hydroxycinnamic and hydroxybenzoic acids, coumarins, xanthones, chalcones, stilbenes, lignins, and lignans have been described in numerous publications regarding the phenolic profile of the genus Carissa. These compounds are known for their important role in cancer treatment [8], hepatoprotective effects [9], and antifungal properties [10]. Some of these biological properties are directly related to the antioxidant activity of these compounds, in accordance with that described by Martins et al. [10].

To the author's best knowledge, there are no previous studies describing the anti-inflammatory activity of C. macrocarpa leaves, stems, or flowers, and only few studies could be found regarding antioxidant, cytotoxic, and antibacterial properties of different extracts obtained from leaves and stems. Moreover, there is no report on C. macrocarpa flowers. Therefore, the aim of the present study was to established the individual phenolic profile of the hydroethanolic extracts obtained from leaves, stems, and flowers of C. macrocarpa, being further correlated with their antioxidant, antibacterial, anti-inflammatory, and cytotoxic properties.

\section{Results and Discussion}

\subsection{Phenolic Profile of the Aerial Parts of C. Macrocarpa}

Table 1 presents the chromatographic characteristics (obtained by HPLC-DAD/ESI-MS) and tentative identification of the phenolic compounds present in the hydroethanolic extracts obtained from leaves, stems, and flowers of C. macrocarpa. The quantification of each identified compound is presented in Table 2. An exemplificative phenolic profile of the hydroethanolic extract prepared from leaves is presented in Figure 1.

Thirty phenolic compounds were tentatively identified in the hydroethanolic extracts prepared from C. macrocarpa leaves, stems, and flowers: nine phenolic acids (chlorogenic, coumaric, and syringic coumaric acid derivatives), thirteen flavonols (kaempherol and quercetin derivatives), and eight flavan-3-ols ((epi)-catechin derivatives). To the author's best knowledge, all the phenolic compounds were tentatively identified for the first time in the hydroethanolic extracts of $C$. macrocarpa.

Phenolic acids were found in higher amounts in the hydroethanolic extract of flowers, and in very close amounts to flavanols in the same extract, while leaves showed the lowest amount of phenolic acids. Four chlorogenic acid derivatives (peaks 1, 5, 6, and 8), four $p$-coumaric acid derivatives (peaks 2 , 4,13 , and 15), and one syringic acid derivative (peak 3 ) were tentatively identified. Peaks 1, 5, 6, and 8 $\left([\mathrm{M}-\mathrm{H}]^{-}\right.$at $m / z$ 353) were tentatively identified as 3-O-caffeoylquinic acid (peak 1), 4-O-caffeoylquinic acid (cis and trans, peak 5 and $\mathbf{6}$, respectively), and 5-O-caffeoylquinic acid (peak 8). The assignments of the different caffeoylquinic acid isomers were made using the hierarchical key system previously reported by Clifford et al. (2003) and Clifford et al. (2005) [11,12]. Moreover, 5-O-caffeoylquinic acid (peak 8) was positively identified in comparison with the available commercial standard. Peaks 2, 4, 13, and $\mathbf{1 5}\left([\mathrm{M}-\mathrm{H}]^{-}\right.$at $\left.m / z 337\right)$ were tentatively identified according to their $\mathrm{MS}^{2}$ fragmentation as cis and trans 3-p-coumaroylquinic acid, and cis and trans 5-p-coumaroylquinic acid, respectively, as previously reported by Clifford et al. (2003) and Clifford et al. (2005) [11,12]. The identification of the compounds $2 / 4,5 / 6$, and $13 / 15$ as cis/trans isomers, was based on experimental results previously published by our research group [13], also following the information described by Clifford and coworkers [14,15] regarding these isomers. The hydroxycinnamoyl cis and trans derivatives were distinguished, after UV irradiation ( $366 \mathrm{~nm}, 24 \mathrm{~h}$ ) of these acids in our laboratory [13]. Compound 3 with $\mathrm{MS}^{2}$ fragments at $m / z 197$ ([syringic acid-H $]^{-}$) resulting from the loss of a hexosyl moiety ( $-162 \mathrm{u}$ ) was tentatively assigned as syringic acid hexoside. 
Table 1. Retention time (Rt), wavelengths of maximum absorption in the visible region $\left(\lambda_{\max }\right)$, mass spectral data, and tentative identification of the phenolic compounds present in the hydroethanolic extracts of $C$. macrocarpa leaves, stems, and flowers.

\begin{tabular}{|c|c|c|c|c|c|}
\hline Peak & Rt (min) & $\lambda \max (\mathrm{nm})$ & {$[\mathbf{M}-\mathbf{H}]^{-}(m / z)$} & $\mathrm{MS}^{2}(m / z)$ & Tentative Identification \\
\hline 1 & 4.65 & 324 & 353 & 191(100),179(45),161(15),135(10) & 3-O-Caffeolyquinic acid \\
\hline 2 & 5.16 & 310 & 337 & $191(100), 173(3), 161(5)$ & cis 3-p-Coumaroylquinic acid \\
\hline 3 & 5.21 & 284 & 359 & 239(95),197(100),181(6),153(10),137(5) & Syringic acid hexoside \\
\hline 4 & 5.34 & 290 & 337 & 191(100),173(5),161(5) & trans 3-p-Coumaroylquinic acid \\
\hline 5 & 6.31 & 287 & 353 & 191(32),173(100),161(5),135(5) & cis 4-O-Caffeolyquinic acid \\
\hline 6 & 6.8 & 325 & 353 & 191(75),173(100),161(12),135(5) & trans 4-O-Caffeolyquinic acid \\
\hline 7 & 7.35 & 281 & 577 & $425(100), 289(13)$ & Type B (epi)catechin dimer \\
\hline 8 & 8.1 & 325 & 353 & 191(100),179(35),161(5),135(5) & 5-O-Caffeolyquinic acid * \\
\hline 9 & 9.01 & 280 & 577 & $425(100), 289(19)$ & Type B (epi)catechin dimer \\
\hline 10 & 9.45 & 266,347 & 755 & $593(20), 285(100)$ & Kaempherol-O-hexoside-O-rutinoside \\
\hline 11 & 10.26 & 280 & 865 & $451(14), 425(16), 407(12), 289(11)$ & Type B (epi)catechin trimer \\
\hline 12 & 11.47 & 280 & 1153 & $865(78), 577(35), 575(43), 289(5)$ & Type B (epi)catechintetramer \\
\hline 13 & 10.77 & 284 & 337 & 191(100),173(5),161(5) & cis 5-p-Coumaroylquinic acid \\
\hline 14 & 11.49 & 280 & 1153 & $865(82), 577(24), 575(36), 289(5)$ & Type B (epi)catechin tetramer \\
\hline 15 & 12.15 & 310 & 337 & 191(100),173(3),161(3) & trans 5-p-Coumaroylquinic acid \\
\hline 16 & 12.41 & 280 & 865 & $451(15), 425(13), 407(17), 289(7)$ & Type B (epi)catechin trimer \\
\hline 17 & 12.9 & 280 & 863 & $711(26), 573(61), 451(12), 411(5), 289(22)$ & Type A (epi)catechin trimer \\
\hline 18 & 13.1 & 267,347 & 739 & $593(100), 285(25)$ & Kaempferol-O-deoxyhexoside-O-deoxyhexosyl-hexoside isomer 1 \\
\hline 19 & 13.35 & 280 & 1153 & $865(54), 577(23), 575(24), 289(5)$ & Type B (epi)catechin tetramer \\
\hline 20 & 13.96 & 265,352 & 755 & 609(100),301(25) & Quercetin-O-deoxyhexoside-O-deoxyhexosyl-hexoside \\
\hline 21 & 14.07 & 266,357 & 739 & $593(100), 285(25)$ & Kaempferol-O-deoxyhexoside-O-deoxyhexosyl-hexoside isomer 2 \\
\hline 22 & 14.7 & 257,352 & 609 & $301(100)$ & Quercetin-O-deoxyhexosyl-hexoside isomer 1 \\
\hline 23 & 15.62 & 280,339 & 739 & $285(100)$ & Kaempferol-O-di-deoxyhexoside-hexoside \\
\hline 24 & 15.95 & 271,344 & 575 & 285(100) & Acetylkaempherol-O-malonylhexoside \\
\hline 25 & 16.09 & 266,357 & 739 & $593(100), 285(25)$ & Kaempferol-O-deoxyhexoside- $O$-deoxyhexosyl-hexoside isomer 3 \\
\hline 26 & 16.39 & 257,348 & 739 & $593(100), 285(25)$ & Kaempferol-O-deoxyhexoside-O-deoxyhexosyl-hexoside isomer 4 \\
\hline 27 & 16.88 & 266,352 & 609 & 301(100) & Quercetin-O-deoxyhexosyl-hexoside isomer 2 \\
\hline 28 & 17.1 & 257,354 & 609 & $301(100)$ & Quercetin-3-O-rutinoside * \\
\hline 29 & 19.17 & 266,346 & 593 & $285(100)$ & Kaempherol-O-deoxyhexosyl-hexoside \\
\hline 30 & 20.32 & 266,346 & 593 & $285(100)$ & Kaempherol-3-O-rutinoside * \\
\hline
\end{tabular}

* Compounds identified and quantified according to their chromatographic characteristics by comparison to those obtained with standard compounds. 
Table 2. Quantification (mg/g of extract) of the phenolic compounds present in the hydroethanolic extracts of C. macrocarpa leaves, stems, and flowers.

\begin{tabular}{|c|c|c|c|}
\hline Peak & Leaves & Stems & Flowers \\
\hline 1 & nd & $0.49 \pm 0.01$ & nd \\
\hline 2 & $0.25 \pm 0.01$ & nd & nd \\
\hline 3 & nd & $0.34 \pm 0.01$ & nd \\
\hline 4 & $0.34 \pm 0.01^{b}$ & nd & $0.6 \pm 0.01^{\mathrm{a}}$ \\
\hline 5 & $0.26 \pm 0.004^{c}$ & $0.61 \pm 0.02^{b}$ & $3.1 \pm 0.1^{\mathrm{a}}$ \\
\hline 6 & $0.5 \pm 0.02^{b}$ & $2.28 \pm 0.02^{a}$ & nd \\
\hline 7 & $2 \pm 0.1^{b}$ & $6.4 \pm 0.2^{\mathrm{a}}$ & nd \\
\hline 8 & nd & nd & $0.17 \pm 0.01$ \\
\hline 9 & nd & $2.88 \pm 0.01$ & nd \\
\hline 10 & nd & nd & $0.48 \pm 0.02$ \\
\hline 11 & $1.9 \pm 0.1^{b}$ & $6.09 \pm 0.02^{a}$ & nd \\
\hline 12 & $2.9 \pm 0.1$ & nd & nd \\
\hline 13 & nd & $0.97 \pm 0.01^{b}$ & $1.21 \pm 0.02^{\mathrm{a}}$ \\
\hline 14 & nd & $7.3 \pm 0.2$ & nd \\
\hline 15 & nd & nd & $0.49 \pm 0.02$ \\
\hline 16 & $1.9 \pm 0.1^{b}$ & $3.7 \pm 0.1^{\mathrm{a}}$ & nd \\
\hline 17 & $1.57 \pm 0.05^{b}$ & $4.9 \pm 0.2^{\mathrm{a}}$ & nd \\
\hline 18 & nd & nd & $\operatorname{tr}$ \\
\hline 19 & $2.2 \pm 0.1^{b}$ & $3.9 \pm 0.1^{\mathrm{a}}$ & nd \\
\hline 20 & $1.79 \pm 0.03$ & $1.03 \pm 0.01$ & nd \\
\hline 21 & nd & nd & $\operatorname{tr}$ \\
\hline 22 & nd & nd & $\operatorname{tr}$ \\
\hline 23 & $1.03 \pm 0.01$ & nd & nd \\
\hline 24 & $1.1 \pm 0.03$ & nd & nd \\
\hline 25 & nd & nd & $\operatorname{tr}$ \\
\hline 26 & nd & nd & $1.6 \pm 0.1$ \\
\hline 27 & $\operatorname{tr}$ & nd & nd \\
\hline 28 & $1.86 \pm 0.04^{b}$ & $2.6 \pm 0.1^{\mathrm{a}}$ & $1.48 \pm 0.01^{\mathrm{c}}$ \\
\hline 29 & nd & nd & $\operatorname{tr}$ \\
\hline 30 & $\operatorname{tr}$ & nd & $1.73 \pm 0.03$ \\
\hline TPA & $1.35 \pm 0.04^{\mathrm{c}}$ & $4.68 \pm 0.01^{b}$ & $5.5 \pm 0.1^{\mathrm{a}}$ \\
\hline TF3O & $12.5 \pm 0.2^{b}$ & $35.1 \pm 0.2^{a}$ & nd \\
\hline TF & $5.7 \pm 0.1^{\mathrm{a}}$ & $3.6 \pm 0.1^{c}$ & $5.3 \pm 0.1^{b}$ \\
\hline TPC & $19.6 \pm 0.3^{b}$ & $43.4 \pm 0.1^{\mathrm{a}}$ & $10.8 \pm 0.2^{c}$ \\
\hline
\end{tabular}

tr-traces; nd-not detected. Standard calibration curves: caffeic acid $\left(\mathrm{y}=168823 \mathrm{x}-161172, \mathrm{R}^{2}=0.9939\right.$; peaks 1, 5, 6, and 8); catechin ( $\mathrm{y}=84950 \mathrm{x}-23200, \mathrm{R}^{2}=0.9999 ;$ peaks $7, \mathbf{9}, \mathbf{1 1}, \mathbf{1 2}, \mathbf{1 4}, \mathbf{1 6}, \mathbf{1 7}$, and 19); $p$-coumaric acid $\left(\mathrm{y}=301950 \mathrm{x}+6966.7, \mathrm{R}^{2}=0.9999\right.$; peaks 2, 4, 13, and 15); quercetin-3-O-glucoside $\left(\mathrm{y}=34843 \mathrm{x}-160173, \mathrm{R}^{2}=\right.$ 0.9998; peaks 20, 21, 24, and 25); quercetin-3-O-rutinoside $\left(\mathrm{y}=13343 \mathrm{x}+76751, \mathrm{R}^{2}=0.9998\right.$; peaks 10, 18, 22, 23, 26, 27, 28, 29, 30, and 31). TPA—-total phenolic acids; TF3O-total flavan-3-ols; TF—total flavonols; TPC—total phenolic compounds.

Flavonol glycoside derivatives of quercetin (MS ${ }^{2}$ fragment at $m / z$ 301) and kaempferol $\left(\mathrm{MS}^{2}\right.$ fragment at $\mathrm{m} / \mathrm{z} 285$ ) were the main molecules present in this family of phenolic compounds. Quercetin-3-O-rutinoside (rutin; peak 28) and kaempferol-3-O-rutinoside (peak 30) were identified upon comparison of their chromatographic characteristics with available commercial standards. These compounds have already been identified in the Apocyneaceae family [16].

Peaks 18, 21, 25, and $26\left([\mathrm{M}-\mathrm{H}]^{-}\right.$at $\left.m / z 739\right)$ and $20\left([\mathrm{M}-\mathrm{H}]^{-}\right.$at $\left.m / z 755\right)$ provided the same consequently fragmentation losses of a deoxyhexosyl unit (146 u) and deoxyhexosyl-hexosyl unit (308 u), indicating the location of each residue on different positions of the aglycones of kaempferol and quercetin, respectively, being tentatively identified as kaempferol-O-deoxyhexoside-O-deoxyhexosyl-hexoside isomers 1, 23, and 4, and quercetin-O-deoxyhexoside-O-deoxyhexosyl-hexoside, respectively. Peak 23 also showed a pseudomolecular ion $[\mathrm{M}-\mathrm{H}]^{-}$at $m / z 739$, presenting a unique $\mathrm{MS}^{2}$ fragment at $m / z 285(-454 \mathbf{u}$, which corresponded to $146+146 \mathfrak{u}+162 \mathfrak{u})$ indicating that the three sugar 
units were linked together in the same oxygen position of the aglycone, and in this particular case, kaempferol, being tentatively identified as kaempferol-O-di-deoxyhexosyl- hexoside. Peak 24 presented a pseudomolecular ion $[\mathrm{M}-\mathrm{H}]^{-}$at $m / z 575$, releasing an $\mathrm{MS}^{2}$ fragment at $m / z 285$, corresponding to the loss of acetyl $(42 \mathrm{u})$, malonyl $(86 \mathrm{u})$, and hexosyl $(162 \mathrm{u})$ residues, being tentatively identified as acetylkaempherol-O-malonylhexoside. Peaks 22 and $27\left([\mathrm{M}-\mathrm{H}]^{-}\right.$at $\mathrm{m} / \mathrm{z}$ 609; $\mathrm{MS}^{2}$ at $m / z$ 301) and $29\left([\mathrm{M}-\mathrm{H}]^{-}\right.$at $\mathrm{m} / \mathrm{z}$ 593; at $\mathrm{m} / \mathrm{z}$ 301) showed a single $\mathrm{MS}^{2}$ fragment that indicated the loss of $308 \mathrm{u}$, corresponding to two sugar units linked together (deoxyhexosyl-hexoside moieties), being tentatively identified as quercetin- $O$-deoxyhexosyl-hexoside isomer 1 and 2, and kaempherol-O-deoxyhexosyl-hexoside, respectively. Peak $10\left([\mathrm{M}-\mathrm{H}]^{-}\right.$at $\left.m / z 755\right)$ fragmented at $m / z$ $593(-162 \mathrm{u}$, hexosyl unit) and 285 (-308 u, deoxyhexosyl-hexoside unit), being tentatively identified as kaempherol-O-hexoside-O-deoxyhexosyl-hexoside.

Flavan-3-ols were the main family of phenolic compounds present in the hydroethanolic extracts of stems of $C$. macrocarpa; not being detected in the flower samples. Peaks 7, 9, 11, 12, 14, 16, 17, and 19 were tentatively identified based on their chromatographic characteristics (pseudomolecular analysis and $\mathrm{MS}^{2}$ fragmentation pattern) coherent with B-type (epi)catechin derivatives. Thus, they were tentatively identified as B-type (epi)catechin dimers (peaks 7 and $\mathbf{9},[\mathrm{M}-\mathrm{H}]^{-}$at $m / z$ 577), trimers (peaks 11 and 16, $[\mathrm{M}-\mathrm{H}]^{-}$at $m / z$ 865), and tetramers (peaks 12, 14, and 19, [M - H $]^{-}$at $m / z$ 1153) [17]. Peak 17 was tentatively identified based on the information found in the literature as a (epi)catechin trimer with a type-A linkage, thus being assigned as an A-type (epi)catechin trimer [18].

The phenolic profile of the three plant parts was relatively similar; nevertheless, they all presented different major compounds. For the leaves, cis 5-p-coumaroylquinic acid (peak 13, $2.9 \mathrm{mg} / \mathrm{g}$ extract) was the major molecule, while trans 5 -p-coumaroylquinic acid (peak $15,7.3 \mathrm{mg} / \mathrm{g}$ extract) was the major compound found in stems, and cis 4-O-caffeolyquinic acid (peak 5, 10.35 $\mu \mathrm{g} / \mathrm{g}$ extract) was the main compound found in flowers.

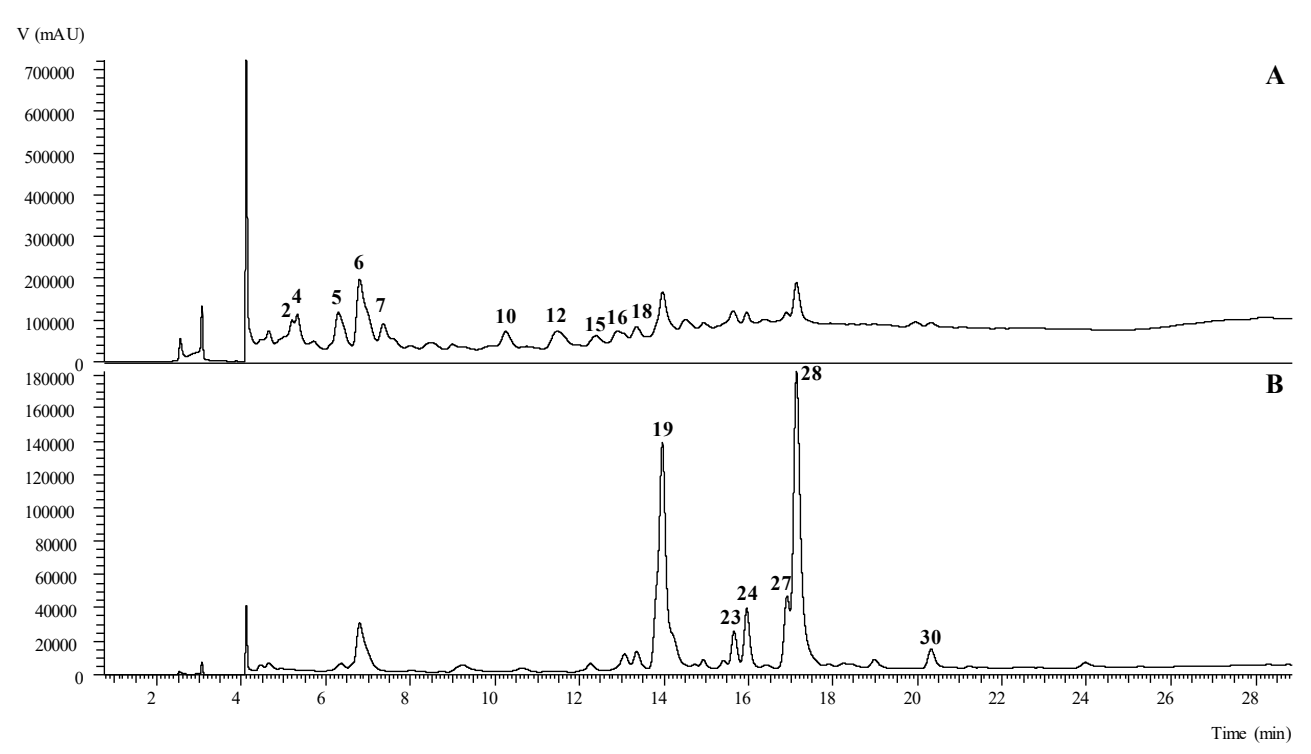

Figure 1. Phenolic profile of the hydroethanolic extract of $C$. macrocarpa leaves recorded at $280 \mathrm{~nm}$ (A) and $370 \mathrm{~nm}$ (B) obtained by HPLC-DAD/ESI-MS.

\subsection{Bioactivities of the Hydroethanolic Extracts of Leaves, Stems, and Flowers}

Results regarding in vitro antioxidant activity of the ethanol/water (80:20 v/v) extracts prepared from leaves, stems, and flowers of C. macrocarpa are described in Table 3. 
Table 3. Antioxidant, cytotoxic, anti-inflammatory, and antibacterial activities of hydroethanolic extracts of $C$. macrocarpa leaves, stems, and flowers, and their correlation with the families of the phenolic compounds identified (mean \pm SD).

\begin{tabular}{|c|c|c|c|c|c|c|c|}
\hline & \multirow{2}{*}{ Leaves } & \multirow{2}{*}{ Stems } & \multirow{2}{*}{ Flowers } & \multicolumn{4}{|c|}{ Correlation Factor $r^{2}$} \\
\hline & & & & TPA & TF3O & $\mathrm{TF}$ & TPC \\
\hline \multicolumn{8}{|l|}{ Antioxidant activity $\mathrm{EC}_{50}$ values $(\mu \mathrm{g} / \mathrm{mL})^{\mathrm{A}}$} \\
\hline DPPH scavenging activity & $26 \pm 1^{b}$ & $281 \pm 1^{\mathrm{a}}$ & $223 \pm 6^{\mathrm{a}}$ & 0.887 & $w / n$ & 0.862 & $\mathrm{~m}$ \\
\hline Reducing power & $36 \pm 1^{\mathrm{b}}$ & $33 \pm 1^{\mathrm{a}}$ & $279 \pm 4^{\mathrm{b}}$ & $w / n$ & 0.940 & $w / n$ & 0.995 \\
\hline$\beta$-carotene bleaching inhibition & $300 \pm 1^{\mathrm{b}}$ & $270 \pm 10^{\mathrm{b}}$ & $1107 \pm 47^{\mathrm{a}}$ & $\mathrm{m}$ & 0.781 & 0.719 & $\mathrm{~m}$ \\
\hline TBARS inhibition & $15.4 \pm 0.1^{\mathrm{b}}$ & $12.1 \pm 0.1^{\mathrm{c}}$ & $92.5 \pm 0.1^{\mathrm{a}}$ & $\mathrm{m}$ & 0.794 & 0.718 & $\mathrm{~m}$ \\
\hline \multicolumn{8}{|l|}{ Cytotoxicity $\mathrm{GI}_{50}$ values $(\mu \mathrm{g} / \mathrm{mL})^{B}$} \\
\hline MCF-7 (breast carcinoma) & $167 \pm 2^{\mathrm{a}}$ & $70.38 \pm 0.03^{c}$ & $95.25 \pm 0.01 \mathrm{~b}$ & 0.862 & $w / n$ & 0.846 & $\mathrm{~m}$ \\
\hline NCI-H460 (non-small cell lung carcinoma) & $120 \pm 1^{\mathrm{a}}$ & $58.7 \pm 0.2^{c}$ & $68 \pm 1^{\mathrm{b}}$ & 0.911 & $w / n$ & 0.898 & $\mathrm{~m}$ \\
\hline HeLa (cervical carcinoma) & $101 \pm 1^{\mathrm{a}}$ & $52.1 \pm 0.3^{c}$ & $75 \pm 1^{\mathrm{b}}$ & 0.721 & $\mathrm{~m}$ & $\mathrm{~m}$ & 0.781 \\
\hline HepG2 (hepatocellular carcinoma) & $152 \pm 3^{\mathrm{a}}$ & $89 \pm 1^{b}$ & $>400$ & 0.943 & $w / n$ & 0.953 & $w / n$ \\
\hline PLP2 (non-tumour porcine liver primary cells) & $>400$ & $>400$ & $>400$ & - & - & - & - \\
\hline \multicolumn{8}{|l|}{ Anti-inflammatory activity $\mathrm{IC}_{50}$ values $(\mu \mathrm{g} / \mathrm{mL}) \mathrm{C}$} \\
\hline NO production & $179 \pm 6^{\mathrm{c}}$ & $208 \pm 9^{\mathrm{a}}$ & $196 \pm 4^{\mathrm{b}}$ & $\mathrm{m}$ & $w / n$ & $w / n$ & $w / n$ \\
\hline \multicolumn{8}{|l|}{ Antibacterial activity MIC values (mg/mL) } \\
\hline \multicolumn{8}{|l|}{ Gram-negative bacteria } \\
\hline Escherichia coli $\mathrm{D}$ & 5 & 10 & 10 & 0.961 & $w / n$ & 0.952 & $w / n$ \\
\hline Escherichia coli $\mathrm{ESBL}^{\mathrm{E}}$ & 20 & 20 & 20 & - & - & - & - \\
\hline Klebsiella pneumoniae D & $>20$ & $>20$ & $>20$ & - & - & - & - \\
\hline Klebsiella pneumoniae ESBL ${ }^{\mathrm{D}}$ & $>20$ & $>20$ & $>20$ & - & - & - & - \\
\hline Morganella morganii ${ }^{\mathrm{D}}$ & 10 & 10 & 20 & 0.720 & 0.772 & 0.774 & $w / n$ \\
\hline Pseudomonas aeruginosa & 20 & 20 & 20 & - & - & - & - \\
\hline \multicolumn{8}{|l|}{ Gram-positive bacteria } \\
\hline Enterococcus faecalis $\mathrm{F}$ & 1.25 & 1.25 & 5 & 0.720 & 0.772 & 0.774 & $w / n$ \\
\hline Listeria monocytogenes $\mathrm{G}$ & 2.5 & 0.625 & 20 & $\mathrm{~m}$ & 0.825 & $\mathrm{~m}$ & $\mathrm{~m}$ \\
\hline MRSA $*, \mathrm{~F}$ & 2.5 & 2.5 & 20 & 0.720 & 0.772 & 0.742 & $\mathrm{~m}$ \\
\hline MSSA $^{\mathrm{F}}$ & 5 & 2.5 & 10 & $w / n$ & 0.938 & $\mathrm{~m}$ & 0.852 \\
\hline
\end{tabular}

A Trolox EC 50 values: $43.03 \pm 1.71 \mu \mathrm{g} / \mathrm{mL}$ (DDPH), $29.62 \pm 3.15 \mu \mathrm{g} / \mathrm{mL}$ (reducing power), $2.63 \pm 0.14 \mu \mathrm{g} / \mathrm{mL}$ ( $\beta$-carotene bleaching inhibition), and $3.73 \pm 1.9 \mu \mathrm{g} / \mathrm{mL}$ (TBARS inhibition); ${ }^{B}$ Ellipticine GI 50 value: $0.91 \pm 0.04 \mu \mathrm{g} / \mathrm{mL}$ (MCF-7), $1.03 \pm 0.09 \mu \mathrm{g} / \mathrm{mL}$ (NCI-H460), $1.91 \pm 0.06 \mu \mathrm{g} / \mathrm{mL}$ (HeLa), $1.1 \pm 0.2 \mu \mathrm{g} / \mathrm{mL}$ (HepG2), and $3.2 \pm 0.7 \mu \mathrm{g} / \mathrm{mL}$ (PLP2); ${ }^{\mathrm{C}}$ Dexamethaxone EC 50 value: $16 \pm 1 \mu \mathrm{g} / \mathrm{mL}$. S-susceptible; I-intermediate; R-resistant. This classification was made according to the interpretative breakpoints suggested by Clinical and Laboratory Standards

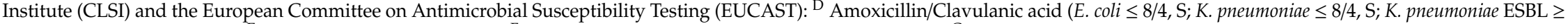

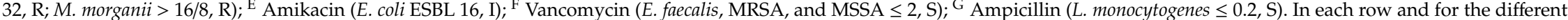
extraction procedure, different letters mean significant differences $(p<0.05)$. Data shown on correlation factor only considered the strong and very strong correlations $((0.7-0.9)$ and $>0.9$, respectively); $\mathrm{m}$-moderate correlations $((0.5-0.7) ; w / n-$ weak and negligible correlations $((0.3-0.5)$ and $(0-0.3)$, respectively). MIC—minimum inhibitory concentration. 
Overall, all samples presented high antioxidant activity, but the statistical analysis did not show significant differences that could allow to particularize a more potent plant part. However, observing the four used methodologies, the leaves presented the lowest $\mathrm{EC}_{50}$ values for DPPH scavenging activity, reducing power, and $\beta$-carotene bleaching inhibition $\left(\mathrm{EC}_{50}=26 \pm 1,36 \pm 1\right.$, and $300 \pm 1$ $\mu \mathrm{g} / \mathrm{mL}$, respectively), while for the TBARS assay, the stems showed the lowest $\mathrm{EC}_{50}$ value $(12.1 \pm$ $0.1 \mu \mathrm{g} / \mathrm{mL}$ ). The antioxidant activity of methanolic extracts from leaves and stems of C. grandiflora originated in Pakistan was previously reported, presenting similar results for DPPH scavenging activity of leaves $(0.2089 \pm \mathrm{mg} / \mathrm{mL})$, but lower results for stems $(0.0615 \mathrm{mg} / \mathrm{mL})$ [4]. The cytotoxic effects of the hydroethanolic extracts prepared from C. macrocarpa were evaluated on non-tumour (PLP2) and four human tumour cell lines, with the results being summarized in Table 3. It can be observed that all samples exhibited anti-proliferative activity on the four tested tumour cell lines with $\mathrm{GI}_{50}$ values ranging between $52.1 \pm 0.3$ and $167 \pm 2 \mu \mathrm{g} / \mathrm{mL}$, with the exception of the hydroethanolic extract of the flowers against HepG2. Unlike the antioxidant activity, the stems showed the lowest $\mathrm{GI}_{50}$ values in all the cell lines studied. It is worthwhile mentioning that any of the samples exhibited toxicity against the normal liver cell line (PLP2), up to the maximal tested concentration $\left(\mathrm{GI}_{50}>400 \mu \mathrm{g} / \mathrm{mL}\right)$. Khatun et al. (2017) [19] investigated C. macrocarpa methanolic extract, which reduced the viability of adenocarcinoma cell lines (SW-480 and SW-48) with $\mathrm{IC}_{50}$ values of 140.6 and $376.6 \mu \mathrm{g} / \mathrm{mL}$, respectively, after $24 \mathrm{~h}$ of treatment, and 108.4 and $290.0 \mu \mathrm{g} / \mathrm{mL}$, respectively, after $48 \mathrm{~h}$ of treatment. Sehar et al. (2011) [20] studied the aqueous extract of C. spinarum stems and its $n$-butanol fraction, which exhibited a potential cytotoxic effect on a wide range of human tumour cell lines, with apoptotic activity in human leukaemia HL-60 cells, through the mitochondrial dependent pathway in HL-60 cells. In addition, the methanolic extract of Carissa opaca Stapf ex Haines leaves and their fractions were tested against MCF-7 breast cancer cell line, indicating that the fractions were more active than the crude extracts [21]. Carandinol extracted from the leaves of C. carandas exhibited significant in vitro cytotoxicity against HeLa, PC-3, and 3T3 cell lines [22]. Lignans, carissanol, carinol, and nortrachelogenin extracted from the stems of C. spinarum displayed cytotoxicity against breast (MCF-7) and lung (A549) tumour cell lines [23].

The results regarding the anti-inflammatory activity of C. macrocarpa hydroethanolic extracts are also summarized in Table 3. All the samples revealed inhibition of the NO production with higher $\mathrm{GI}_{50}$ values in comparison with the positive control, and it can be verified that the highest activity was observed in the leaves $\left(\mathrm{GI}_{50}=179 \pm 6 \mu \mathrm{g} / \mathrm{mL}\right)$. To the author's best knowledge, there are no previous reports regarding the anti-inflammatory activity of $C$. macrocarpa. However, the anti-inflammatory activity of naringin isolate from the leaves of $C$. carandas was investigated in vivo by a carrageenan induced hind rat pawedema model and in vitro by measuring its inhibitory effect on LPS induced release of NO from RAW 264.7 macrophages. The results showed that naringin (compound not found in our samples) exhibited potent inhibition of inflammation and inhibited LPS induced release of NO from macrophages $\left(\mathrm{IC}_{50}=6.4 \mu \mathrm{M}\right)$ [24].

The hydroethanolic extracts of leaves, stems, and flowers of C. macrocarpa were tested for their antimicrobial activity against selected clinical isolates, representing both Gram-positive and Gram-negative bacteria. The results of the obtained minimum inhibitory concentration (MIC) values of the hydroethanolic extracts of C. macrocarpa are presented in Table 3. Gram-positive bacteria were more sensitive to the extracts presenting lower MIC values ranging from 0.625 to $20 \mathrm{mg} / \mathrm{mL}$, and were more susceptible to both leaves and stems. The best results among Gram-negative bacteria were observed for Escherichia coli ESBL and Morganella morganii. Regarding Klebsiella pneumoniae and Klebsiella pneumoniae ESBL, the extracts did not express any activity up to the maximal tested concentration. The antibacterial activity of C. macrocarpa extracts is supported by the studies performed by Abbas et al. (2014) [4], which reported a higher MIC value in the methanolic extracts of $C$. macrocarpa stems and leaves against three pathogenic microorganisms (E. coli, Staphylococcus aureus, and Staphylococcus epidermidis), with MIC values ranging between 0.39 and $1.88 \mathrm{mg} / \mathrm{mL}$. 
Table 3 also presents the Pearson's correlation analysis between the bioactivities and the sum of total phenolic acid derivatives, total flavan-3-ols, total flavonols, and total phenolic compounds. The results with a confidence level below $70 \%$ are not shown in the table, being classified as a moderate correlation (confidence level between 50\% and 70\%) and weak and negligible correlations (confidence level between $50 \%$ and $30 \%$ and between $30 \%$ and $0 \%$, respectively). Regarding antioxidant activity, it can be observed that flavan-3-ols had the highest correlations with $\beta$-carotene bleaching inhibition and TBARS assay $\left(r^{2}=0781\right.$, and 0794, respectively), while DPPH scavenging activity presented a higher correlation to the phenolic acids $\left(r^{2}=0.887\right)$, and reducing power to the total phenolic compounds $\left(r^{2}=0.995\right)$. The antioxidant potential of flavan-3-ols derivatives has been widely reported [25]; however, because of the structural diversity of these type of compounds, their in vivo activity can be very different, which is the reason they did not correlate so strongly with the biochemical assay of $\beta$-carotene bleaching inhibition and TBARS. Regarding the cytotoxic activity, phenolic acids showed correlations with all the studied cell lines, although showing a higher correlation with MCF-7 and NCI-H460 ( $r^{2}=0.862$ and 0.911, respectively). For HeLa and HepG2 cell lines, the highest correlation levels were observed with total phenolic compounds $\left(r^{2}=0.781\right)$ and flavonols $\left(r^{2}=0.953\right)$, respectively. Finally, the correlations on the antimicrobial activity revealed that it is with Gram-negative bacteria that phenolic compounds correlate more, with values that ranged between $r^{2}=0.720$ and 0.938. However, the results obtained for E. coli showed a correlation level of $r^{2}=0.961$ and $r^{2}=0.952$ with the phenolic acids and flavonols, respectively, a much higher correlation than those observed for the other Gram-negative bacteria. In the groups of phenolic acids and flavonols, no compound stood out and, therefore, perhaps synergetic effects of all compounds are responsible for the high correlations observed. However, the biological properties of hydroxycinnamic acids and quercetin and kaempferol derivatives have already been abundantly observed and described; notwithstanding, the synergies that occur in natural extracts may favour the biological properties.

\section{Materials and Methods}

\subsection{Plant Material and Preparation of the Hydroethanolic Extracts}

The samples of Carissa macrocarpa (Eckl.) A.DC. (leaves, stems, and flowers) were collected in Monastir, Tunisia during 2016. The samples were dried until at a constant weight in an incubator at $35^{\circ} \mathrm{C}$. Then, the plant material was ground to approximately $40 \mathrm{mesh}$, and the homogeneous samples were stored in a desiccator protected from light.

The hydroalcoholic extract was obtained by maceration using aqueous ethanolic solution (80\%, $v / v ; 30 \mathrm{~g} / \mathrm{mL}$ ) as the extraction solvent, applying the previous conditions reported by the authors (Barros et al., 2013). After filtration (Whatman $n^{\circ} 4$ filter), the solvent was first evaporated at $40{ }^{\circ} \mathrm{C}$, under reduced pressure, in a rotary evaporator (Büchi R-210, Flawil, Switzerland) and the residual solvent was removed in a freeze drier $\left(-49^{\circ} \mathrm{C}, 0.089\right.$ bar, during 48 h, FreeZone 4.5 , Labconco, Kansas City, MO, USA).

\subsection{Phenolic Profile of the Hydroethanolic Extracts of Leaves, Stems, and Flowers}

The dry extracts were re-suspended at a concentration of $5 \mathrm{mg} / \mathrm{mL}$ using aqueous ethanol $(80 \%$, $v / v)$ and filtered (0.2 $\mu \mathrm{m}$ disposable LC filter disk, $30 \mathrm{~mm}$, nylon). Afterwards, the phenolic profile was found by liquid chromatography with a diode-array detector (280, 330, and 370 nm wavelengths) coupled to an electrospray ionization mass spectrometry operating in negative mode (Dionex Ultimate 3000 UPLC and Linear Ion Trap LTQ XL, Thermo Scientific, San Jose, CA, USA), as previously described by the authors [26]. The phenolic compounds were identified according to their chromatographic characteristics by comparison with those obtained with standard compounds and with literature. Calibration curves of appropriate standards were obtained in the range of $200-5 \mu \mathrm{g} / \mathrm{mL}$ for the quantitative analysis. The results were expressed in $\mathrm{mg}$ per $\mathrm{g}$ of extract $(\mathrm{mg} / \mathrm{g})$. 


\subsection{Bioactivities of the Hydroethanolic Extracts of Leaves, Stems, and Flowers}

\subsubsection{Antioxidant Activity}

The extracts were diluted in distilled water at a concentration of $10 \mathrm{mg} / \mathrm{mL}$; then, successive dilutions were carried out (5000 and $6.25 \mu \mathrm{g} / \mathrm{mL}$ ). The DPPH radical-scavenging activity, reducing power, inhibition of $\beta$-carotene bleaching, and TBARS assay were the methodologies applied to determine the antioxidant activity [27]. The results were expressed as $\mathrm{EC}_{50}$ values (sample concentration providing $50 \%$ of antioxidant activity) and Trolox was used as a positive control.

\subsubsection{Cytotoxic Activity}

The extracts were re-dissolved in water at a $8 \mathrm{mg} / \mathrm{mL}$ concentration and further diluted in the range of 400 to $6.25 \mu \mathrm{g} / \mathrm{mL}$. The cytotoxic properties were evaluated using four human tumor cell lines: MCF-7 (breast adenocarcinoma), NCI-H460 (non-small cell lung cancer), HeLa (cervical carcinoma), and HepG2 (hepatocellular carcinoma). A non-tumor cell line (PLP2) was also evaluated using a procedure previously described in Abreu et al. (2011) [28]. Sulforhodamine B assay was carried out [29], with Ellipticine used as positive control, and a negative control was provided by each suspension of cells. The results were expressed in $\mathrm{GI}_{50}$ values (concentration that inhibited 50\% of the cell proliferation).

\subsubsection{Anti-Inflammatory Activity}

The extracts were re-dissolved in water at a concentration of $8 \mathrm{mg} / \mathrm{mL}$ and then diluted in the range of 400 to $6.25 \mu \mathrm{g} / \mathrm{mL}$. A mouse macrophage-like cell line RAW 264.7 was used in this study and the Griess Reagent System (GRS) kit was applied to determine the nitric oxide, measured at $515 \mathrm{~nm}$ (ELx800 microplate reader, Bio-Tek Instruments, Inc; Winooski, VT, USA), as described previously [30]. The results were expressed in $\mathrm{EC}_{50}$ values (sample concentration providing $50 \%$ of inhibition of $\mathrm{NO}$ production) and Dexamethasone was used as a positive control, while in negative controls, no LPS was added.

\subsubsection{Antibacterial Activity}

The extracts were re-dissolved in water to obtain a stock solution of $100 \mathrm{mg} / \mathrm{mL}$ and then diluted in the range of 20 to $1.25 \mu \mathrm{g} / \mathrm{mL}$. The antimicrobial potential of the extracts was assessed using five Gram-negative bacteria and three Gram-positive bacteria. For each bacteria, the minimum inhibitory concentration (MIC) and minimum bactericidal concentration (MBC) were determined using a colorimetric assay, as described by Svobodova et al. (2017) [31].

\subsection{Statistical Analysis}

Triplicates of the samples were assayed and three repetitions of each methodology were performed, with the results being expressed as mean values and standard deviations (SD). The significant differences between samples were evaluated using one-way analysis of variance (ANOVA) followed by Tukey's HSD Test with $p=0.05$ (SPSS v. 23.0 program); when there were less than three samples, a Student's $t$-test was applied $(p=0.05)$. Furthermore, a Pearson's correlation analysis between the bioactivities and all the sum contents of the analysed compounds (total phenolic acid derivatives, total flavan-3-ols, total flavonols, and total phenolic compounds) was carried out, with a 95\% confidence level.

\section{Conclusions}

The results obtained showed that the different parts of C. macrocarpa can be used as sources of phenolic compounds, with high bioactive potential to be exploited in the development of novel pharmaceutical formulations, for example. Overall, among the thirty phenolic compounds identified in the hydroethanolic extracts prepared from leaves, stems, and flowers of $C$. macrocarp, three distinct families were found: phenolic acids, flavan-3-ols, and flavonols. The last-mentioned group presented 
the highest number of identified compounds; thus, flavan-3-ols showed the highest concentration in stems (mainly owing to the presence of dimers, trimmers, and tetramers of (epi)-catechin). The phenolic acids were found in higher amounts in flowers, mainly owing to the presence of 4-O-caffeoylquinic acid. Leaves were distinguished by their high antioxidant and anti-inflammatory activity, as well as bactericidal activity against $E$. coli. Stems presented a high cytotoxic activity and bactericidal effect against Gram-positive bacteria. The high correlation between the bioactivities studied and the presence of phenolic compounds was also proven, which meets consumer expectations about their health and well-being. Overall, the underexplored parts of $C$. macrocarpa presented high intrinsic bioactive properties, such as antioxidant, cytotoxic, anti-inflammatory, and antimicrobial activities, potentiated by the presence of phenolic compounds. The added value of this plant can lead to its application in several industries, with different outputs.

Author Contributions: Formal analysis, L.B.; Investigation, F.S.; Methodology, R.C.C. and M.J.A.; Supervision, F.H.-S. and I.C.F.R.F.; Writing—original draft, M.I.D.; Writing—review \& editing, I.C.F.R.F.

Funding: The authors are grateful to the Foundation for Science and Technology (FCT, Portugal) and FEDER under Programmer PT2020 for financial support to CIMO (UID/AGR/00690/2019); L. Barros and M.I. Dias thank the national funding by FCT, P.I., through the institutional scientific employment program-contract for their contracts. The authors are also grateful to FEDER-Interreg España-Portugal programme for financial support through the project 0377_Iberphenol_6_E.

Conflicts of Interest: The authors declare no conflict of interest.

\section{References}

1. Patel, S. Food, pharmaceutical and industrial potential of Carissa genus: An overview. Rev. Environ. Sci. Biotechnol. 2013, 12, 201-208. [CrossRef]

2. Moodley, R.; Koorbanally, N.; Jonnalagadda, S.B. Elemental composition and fatty acid profile of the edible fruits of Amatungula (Carissa macrocarpa) and impact of soil quality on chemical characteristics. Anal. Chim. Acta 2012, 730, 33-41. [CrossRef]

3. Khalil, E.; Aljeshi, Y.M.; Saleh, F.A. Authentication of Carissa macrocarpa Cultivated in Saudi Arabia; Botanical, Phytochemical and Genetic Study. J. Pharm. Sci. Res. 2015, 7, 497-508.

4. Abbas, M.; Rasool, N.; Riaz, M.; Zubair, M.; Abbas, M.; Ul-Haq, N.; Hayat, N. GC-MS profiling, antioxidant, and antimicrobial studies of various parts of Carissa grandiflora. Bulg. Chem. Commun. 2014, 46, 831-839.

5. Council, N.R. Lost Crops of Africa: Volume III: Fruits; National Academies Press: Washington, DC, USA, 2008.

6. Moodley, R.; Chenia, H.; Jonnalagadda, S.B. Antibacterial and anti-adhesion activity of the pentacyclic triterpenoids isolated from the leaves and edible fruits of Carissa macrocarpa. J. Med. Plant Res. 2011, 5, 4851-4858.

7. Khalil, H.; Mohamed, M.; Morsy, M.; Kandeel, M. Flavonoid and Phenolic Compounds from Carissa macrocarpa: Molecular Docking and Cytotoxicity Studies. Pharmacogn. Mag. 2018, 14, 304. [CrossRef]

8. Carocho, M.; Ferreira, I.C.F.R. The role of phenolic compounds in the fight against cancer-A review. Anticancer. Agents Med. Chem. 2013, 13, 1236-1258. [CrossRef]

9. Pereira, C.; Barros, L.; Ferreira, I.C. Extraction, identification, fractionation and isolation of phenolic compounds in plants with hepatoprotective effects. J. Sci. Food Agric. 2016, 96, 1068-1084. [CrossRef]

10. Martins, N.; Barros, L.; Henriques, M.; Silva, S.; Ferreira, I.C.F.R. Activity of phenolic compounds from plant origin against Candida species. Ind. Crops Prod. 2015, 74, 648-670. [CrossRef]

11. Clifford, M.N.; Johnston, K.L.; Knight, S.; Kuhnert, N. Hierarchical scheme for LC-MSnidentification of chlorogenic acids. J. Agric. Food Chem. 2003, 51, 2900-2911. [CrossRef] [PubMed]

12. Clifford, M.N.; Knight, S.; Kuhnert, N. Discriminating between the six isomers of dicaffeoylquinic acid by LC-MSn. J. Agric. Food Chem. 2005, 53, 3821-3832. [CrossRef] [PubMed]

13. Barros, L.; Dueñas, M.; Carvalho, A.M.; Ferreira, I.C.F.R.; Santos-Buelga, C. Characterization of phenolic compounds in flowers of wild medicinal plants from Northeastern Portugal. Food Chem. Toxicol. 2012, 50, 1576-1582. [CrossRef] 
14. Clifford, M.N.; Zheng, W.; Kuhnert, N. Profiling the chlorogenic acids of aster by HPLC-MSn. Phytochem. Anal. 2006, 17, 384-393. [CrossRef] [PubMed]

15. Clifford, M.N.; Wu, W.; Kirkpatrick, J.; Kuhnert, N. Profiling the chlorogenic acids and other caffeic acid derivatives of herbal chrysanthemum by LC-MSn. J. Agric. Food Chem. 2007, 55, 929-936. [CrossRef] [PubMed]

16. Heneidak, S.; Grayer, R.J.; Kite, G.C.; Simmonds, M.S.J. Flavonoid glycosides from Egyptian species of the tribe Asclepiadeae (Apocynaceae, subfamily Asclepiadoideae). Biochem. Syst. Ecol. 2006, 34, 575-584. [CrossRef]

17. Dias, M.I.; Barros, L.; Fernandes, I.P.; Ruphuy, G.; Oliveira, M.B.P.; Santos-Buelga, C.; Barreiro, M.F.; Ferreira, I.C.F.R. A bioactive formulation based on Fragaria vesca L. vegetative parts: Chemical characterisation and application in K-carrageenan gelatin. J. Funct. Foods 2015, 16, 243-255. [CrossRef]

18. Zhang, S.; Zhu, M. Characterization of Polyphenolics in Grape Pomace Extracts Using ESI Q-TOF MS/MS. HSOA J. Food Sci. Nutr. 2015, 1, 1-10.

19. Khatun, M.; Habib, M.R.; Rabbi, M.A.; Amin, R.; Islam, M.F.; Nurujjaman, M.; Karim, M.R.; Rahman, M.H. Antioxidant, cytotoxic and antineoplastic effects of Carissa carandas Linn. leaves. Exp. Toxicol. Pathol. 2017, 69, 469-476. [CrossRef]

20. Sehar, I.; Pal, H.C.; Shukla, S.; Bhushan, S.; Hamid, A.; Gupta, B.D.; Saxena, A.K. Cytotoxic evaluation and induction of mitochondria-mediated apoptosis in human leukaemia HL-60 cells by Carissa spinarum stem isolate. J. Pharm. Pharmacol. 2011, 63, 1078-1090. [CrossRef]

21. Nisa, S.; Bibi, Y.; Zia, M.; Waheed, A.; Pharm Sci, P.J.; Fayyaz Chaudhary, M. Anticancer investigations on Carissa opaca and Toona ciliata extracts against human breast carcinoma cell line Biological evaluation and chemical fingerprint of plant-derived materials View project medicinal plant View project Anticancer inv. Pak. J. Pharm. Sci. 2013, 26, 1009-1012.

22. Begum, S.; Syed, S.A.; Siddiqui, B.S.; Sattar, S.A.; Choudhary, M.I. Carandinol: First isohopane triterpene from the leaves of Carissa carandas L. and its cytotoxicity against cancer cell lines. Phytochem. Lett. 2013, 6, 91-95. [CrossRef]

23. Wangteeraprasert, R.; Lipipun, V.; Gunaratnam, M.; Neidle, S.; Gibbons, S.; Likhitwitayawuid, K. Bioactive Compounds from Carissa spinarum. Phyther. Res. 2012, 26, 1496-1499. [CrossRef]

24. El-desoky, A.H.; Abdel-Rahman, R.F.; Ahmed, O.K.; El-Beltagi, H.S.; Hattori, M. Anti-inflammatory and antioxidant activities of naringin isolated from Carissa carandas L.: In vitro and in vivo evidence. Phytomedicine 2018, 42, 126-134. [CrossRef]

25. Monagas, M.; Garrido, I.; Lebrón-Aguilar, R.; Gómez-Cordovés, M.C.; Rybarczyk, A.; Amarowicz, R.; Bartolomé, B. Comparative Flavan-3-ol Profile and Antioxidant Capacity of Roasted Peanut, Hazelnut, and Almond Skins. J. Agric. Food Chem. 2009, 57, 10590-10599. [CrossRef]

26. Bessada, S.M.F.; Barreira, J.C.M.; Barros, L.; Ferreira, I.C.F.R.; Oliveira, M.B.P.P. Phenolic profile and antioxidant activity of Coleostephus myconis (L.) Rchb.f.: An underexploited and highly disseminated species. Ind. Crops Prod. 2016, 89, 45-51. [CrossRef]

27. Sarmento, A.; Barros, L.; Fernandes, Â.; Carvalho, A.M.; Ferreira, I.C. Valorization of traditional foods: Nutritional and bioactive properties of Cicer arietinum L. and Lathyrus sativus L. pulses. J. Sci. Food Agric. 2015, 95, 179-185. [CrossRef]

28. Abreu, R.M.V.; Ferreira, I.C.F.R.; Calhelha, R.C.; Lima, R.T.; Vasconcelos, M.H.; Adega, F.; Chaves, R.; Queiroz, M.-J.R.P. Anti-hepatocellular carcinoma activity using human HepG2 cells and hepatotoxicity of 6-substituted methyl 3-aminothieno[3,2-b]pyridine-2-carboxylate derivatives: In vitro evaluation, cell cycle analysis and QSAR studies. Eur. J. Med. Chem. 2011, 46, 5800-5806. [CrossRef]

29. Barros, L.; Pereira, E.; Calhelha, R.C.; Dueñas, M.; Carvalho, A.M.; Santos-Buelga, C.; Ferreira, I.C.F.R. Bioactivity and chemical characterization in hydrophilic and lipophilic compounds of Chenopodium ambrosioides L. J. Funct. Foods 2013, 5, 1732-1740. [CrossRef]

30. Souilem, F.; Fernandes, Â.; Calhelha, R.C.; Barreira, J.C.M.; Barros, L.; Skhiri, F.; Martins, A.; Ferreira, I.C.F.R. Wild mushrooms and their mycelia as sources of bioactive compounds: Antioxidant, anti-inflammatory and cytotoxic properties. Food Chem. 2017, 230, 40-48. [CrossRef] 
31. Svobodova, B.; Barros, L.; Calhelha, R.C.; Heleno, S.; Alves, M.J.; Walcott, S.; Bittova, M.; Kuban, V.; Ferreira, I.C.F.R. Bioactive properties and phenolic profile of Momordica charantia L. medicinal plant growing wild in Trinidad and Tobago. Ind. Crops Prod. 2017, 95, 365-373. [CrossRef]

Sample Availability: The lyophilized samples are available in our laboratory.

(C) 2019 by the authors. Licensee MDPI, Basel, Switzerland. This article is an open access article distributed under the terms and conditions of the Creative Commons Attribution (CC BY) license (http://creativecommons.org/licenses/by/4.0/). 